\title{
Publisher Correction: Estimating Changes in Forest Attributes and Enhancing Growth Projections: a Review of Existing Approaches and Future Directions Using Airborne 3D Point Cloud Data
}

\author{
Piotr Tompalski ${ }^{1}$ - Nicholas C. Coops ${ }^{1}$ • Joanne C. White ${ }^{2}$. Tristan R. H. Goodbody ${ }^{1}$ - Chris R. Hennigar ${ }^{3}$. \\ Michael A. Wulder ${ }^{2}$. Jarosław Socha ${ }^{4} \cdot$ Murray E. Woods ${ }^{5}$
}

Published online: 19 March 2021

(C) Springer Nature Switzerland AG 2021

\section{Publisher Correction: Current Forestry Reports}

$$
\text { https://doi.org/10.1007/s40725-021-00135-w }
$$

The original version of this article unfortunately contained production errors in the email address of the corresponding author and in Figs. 1-5. The correct email address of the corresponding author is piotr.tompalski@ubc.ca and the corrected figures are shown here.

The original article has been corrected.

Publisher's Note Springer Nature remains neutral with regard to jurisdictional claims in published maps and institutional affiliations.

The online version of the original article can be found at https://doi.org/ 10.1007/s40725-021-00135-w

Piotr Tompalski

piotr.tompalski@ubc.ca

1 Integrated Remote Sensing Studio, Department of Forest Resources Management, University of British Columbia, 2424 Main Mall, Vancouver, BC V6T 1Z4, Canada

2 Canadian Forest Service (Pacific Forestry Centre), Natural Resources Canada, 506 West Burnside Road, Victoria, BC V8Z 1M5, Canada

3 New Brunswick Department of Natural Resources, 1350 Regent St, Fredericton, NB E3C 2G6, Canada

4 Department of Forest Resources Management, Faculty of Forestry, University of Agriculture in Krakow, Al. 29-listopada 46,

31-425 Krakow, Poland

5 Ontario Ministry of Natural Resources and Forestry (Retired), 3301 Trout Lake Road, North Bay, ON P1A 4L7, Canada 
Fig. 1 Overview of the two approaches used to characterize change in forest attributes. The first approach utilizes two or more point cloud datasets to

retrospectively estimate growth rates. In the second approach, the point cloud datasets or derived attribute estimates are integrated into models that forecast contemporary forest attributes into the future
Stand development through time $\longrightarrow$

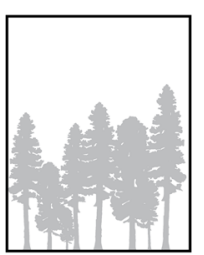

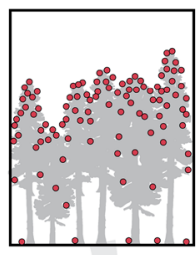

Acquisition 1

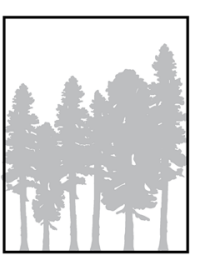

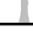

Acquisition 2

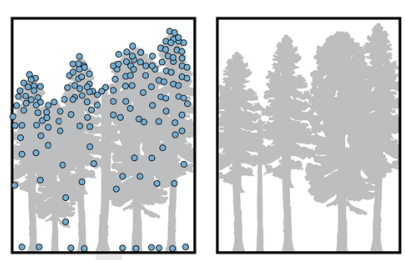

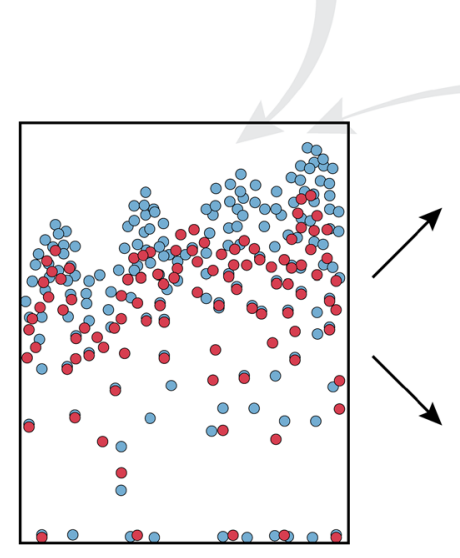

Retrospectively estimating growth

- point cloud-based change estimates

- area-based or tree-level detail

- direct / indirect approaches

Forecasting forest attributes into the future

- growth simulators and productivity models

- plot / curve matching approaches

- developing growth functions 
Fig. 2 Approaches used to estimate past change in forest inventory attributes. Growth can be estimated using CHM differencing, area-based, and individual tree-level analysis
Forest stand at two points in time
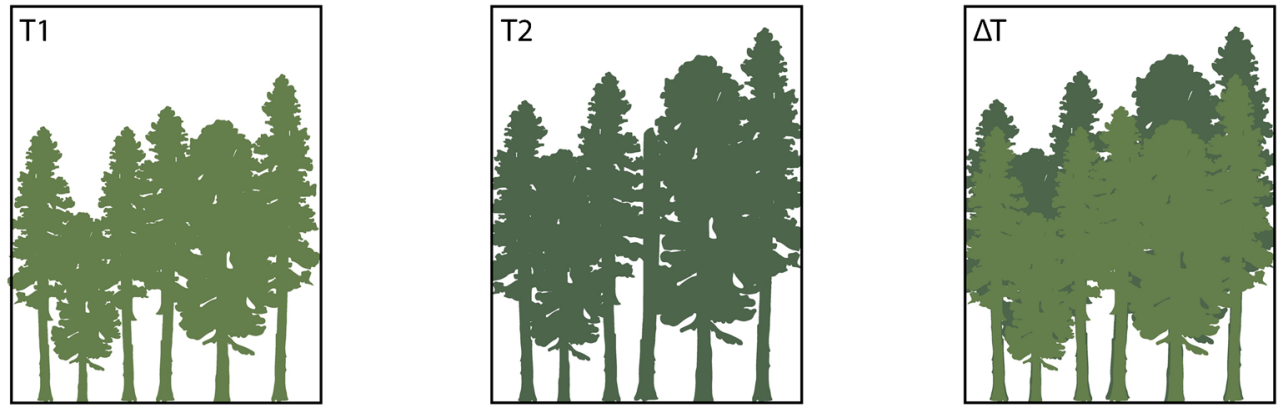

\section{CHM differencing}
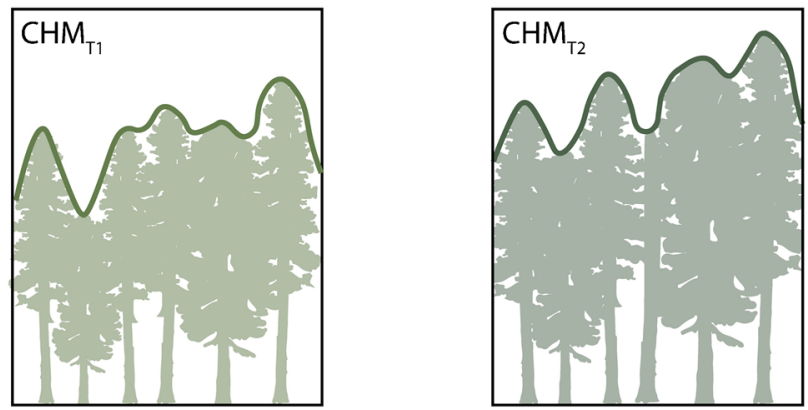

Area-based analysis
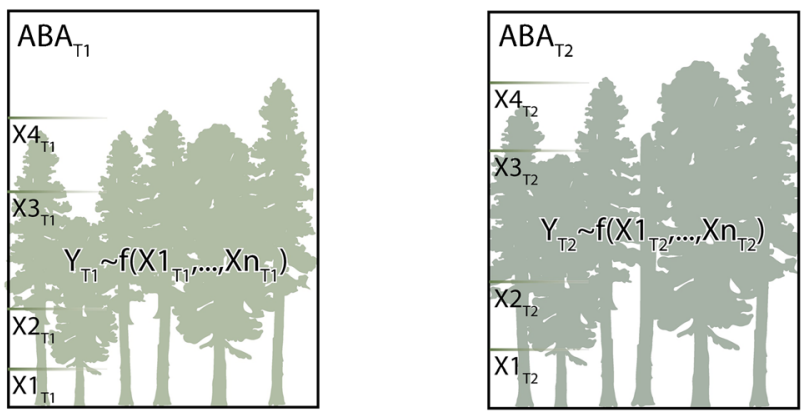

Individual tree-level analysis
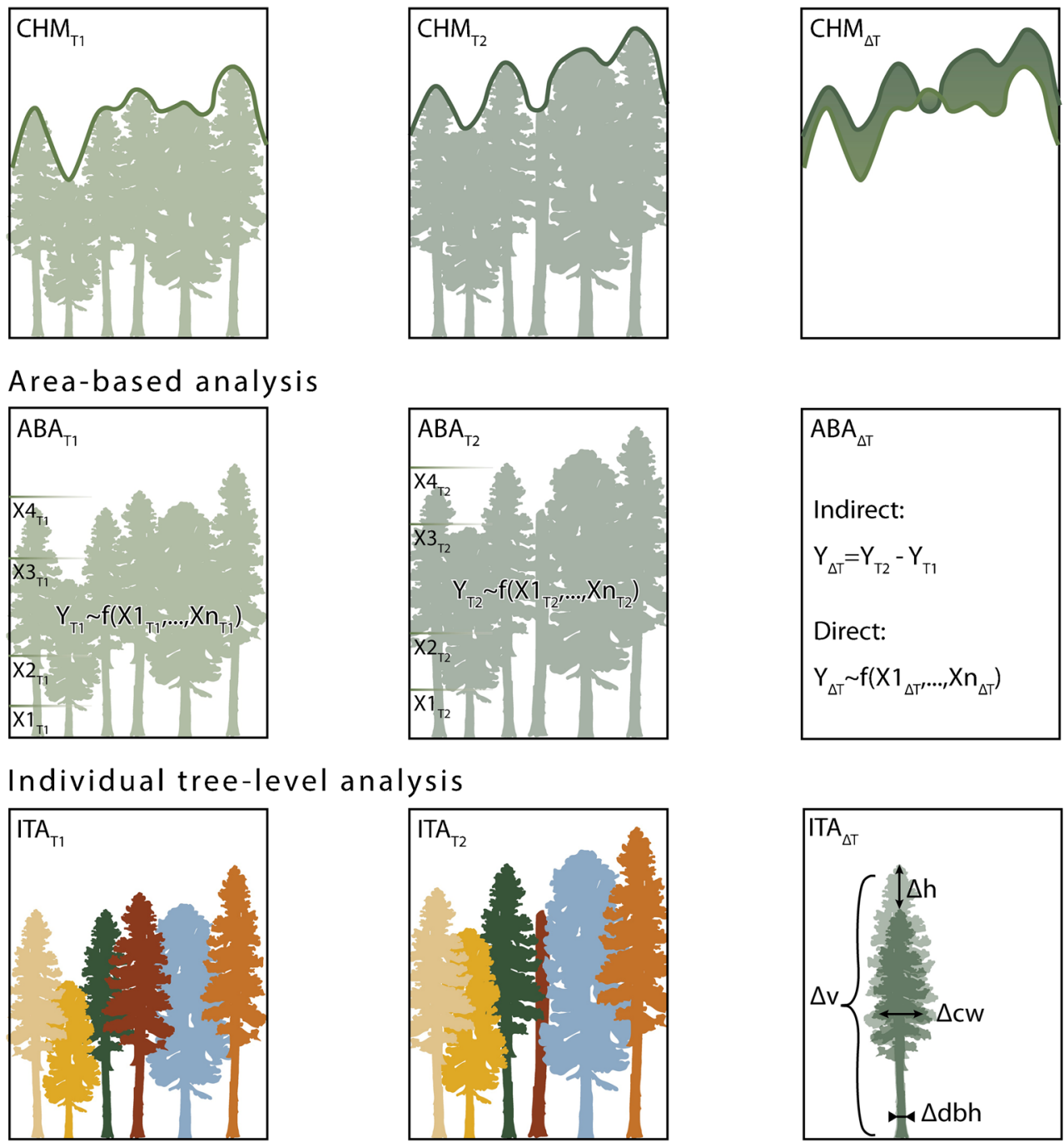

\section{$\mathrm{ABA}_{\Delta \mathrm{T}}$}

Indirect:

$\mathrm{Y}_{\Delta \mathrm{T}}=\mathrm{Y}_{\mathrm{T} 2}-\mathrm{Y}_{\mathrm{T} 1}$

Direct:

$\mathrm{Y}_{\Delta \tau} \sim \mathrm{f}\left(\mathrm{X} 1_{\Delta T}, \ldots, \mathrm{Xn_{ \Delta T }}\right)$

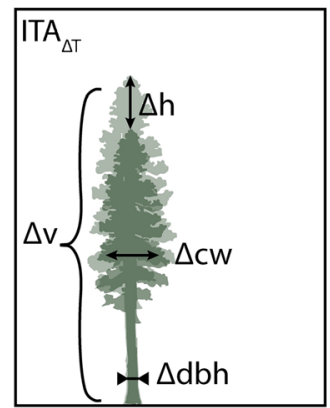


Fig. 3 Summary of studies describing the use of bi- or multitemporal point cloud data for estimating change in forest attributes at the cell and tree level. Circles and squares indicate the data acquisition year for ALS and DAP, respectively. Colors indicate attributes of interest. $\triangle \mathrm{AGB}$, change in above ground biomass; $\Delta \mathrm{H}$, change in height (plot or tree level); other, change in other attributes, including change in volume, change in crown volume, change in crown area, and change in basal area. The " $x$ " symbol indicates that point density was not available (e.g., Land, Vegetation, and Ice Sensor (LVIS) data)

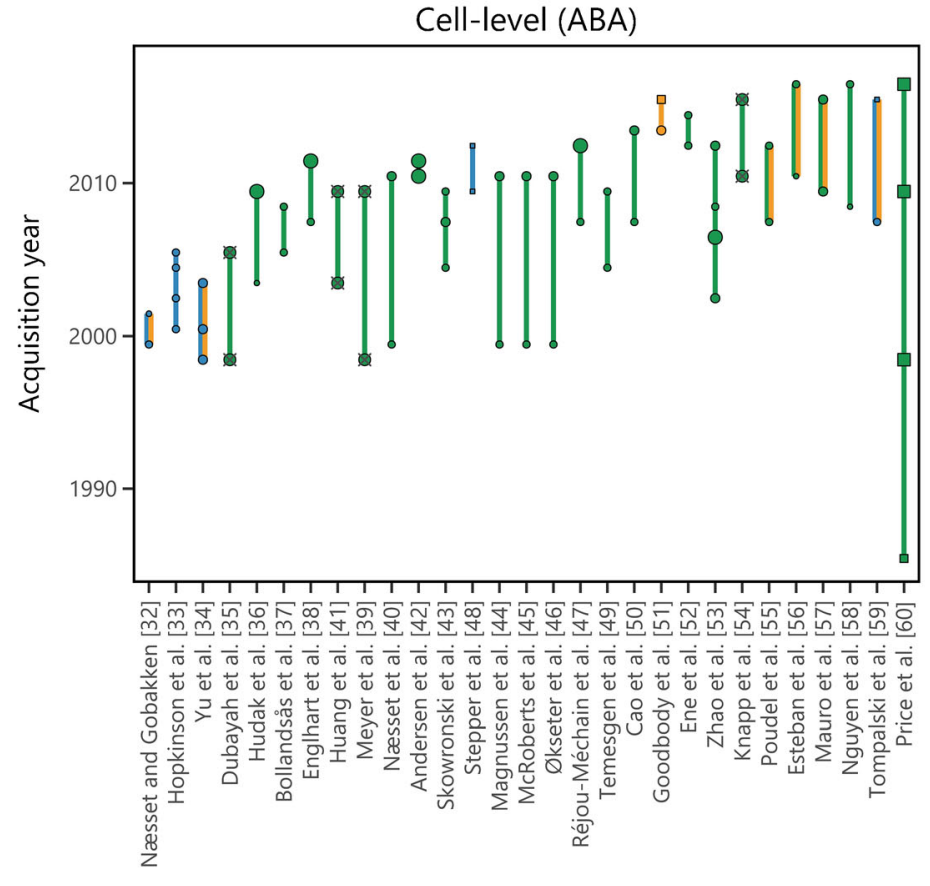

Tree-level (ITA)

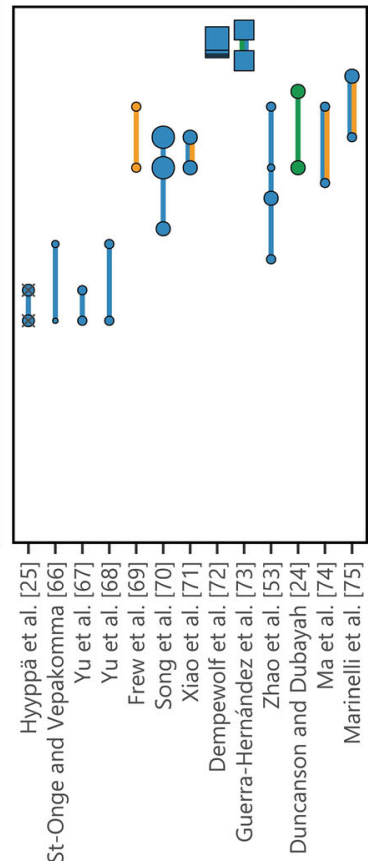

Point density
Data:

Attribute:
- ALS a DAP
| $\triangle A G B \quad \Delta H \quad \mid$ Other
- 1 - 5 - 10
$50 \bigcirc 150$ 
Fig. 4 Approaches to integrate growth simulators with point cloud data to forecast forest inventory attributes. ABA, areabased approach
A. Parametrizing a growth simulator

Point cloud-derived

input parameters

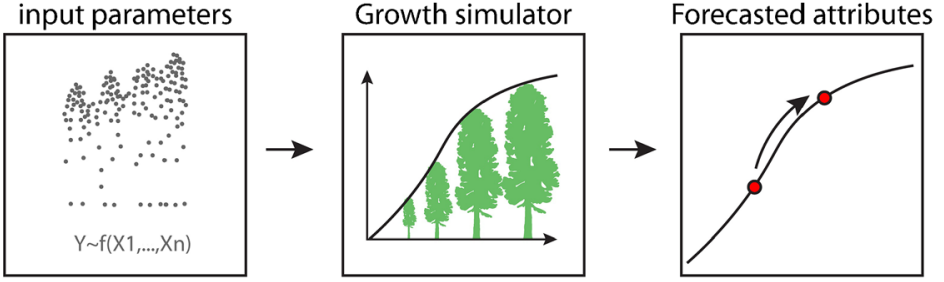

\section{B. Tree list matching}

Database of tree lists

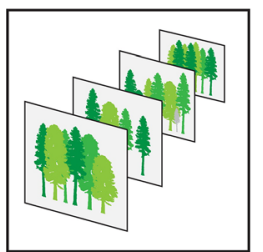

ABA layers

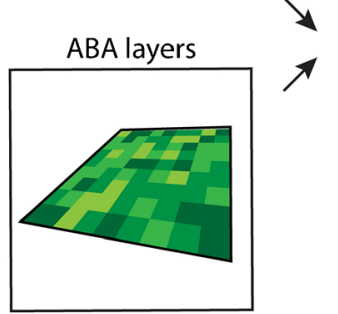

\section{Curve matching}

Growth simulator

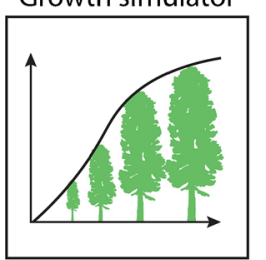

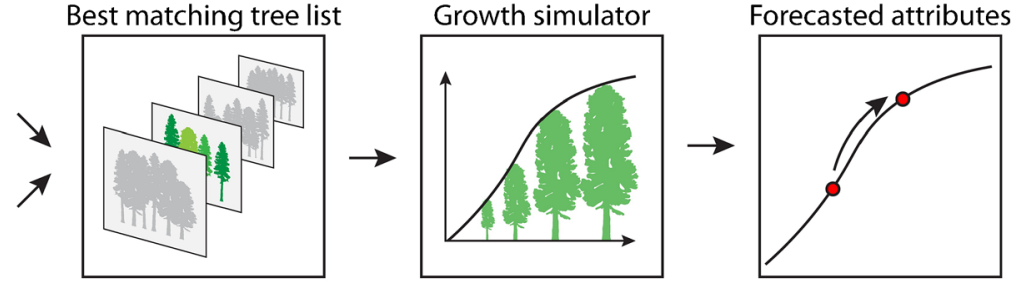

Growth simulator

recasted attributes
Database of yield curves

Best matching yield curve

Forecasted attributes
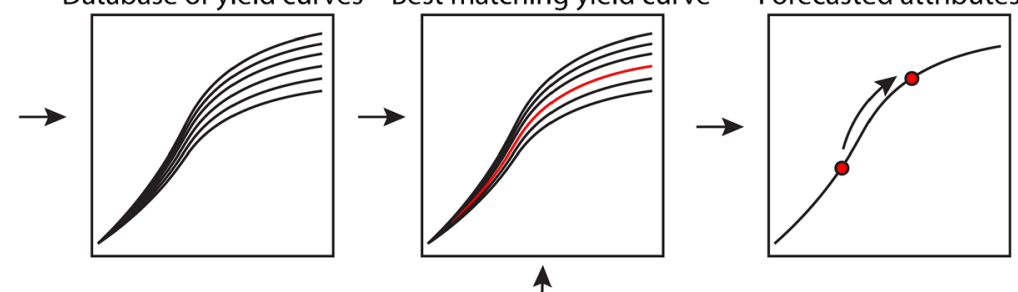

ABA layers

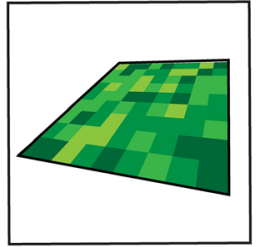



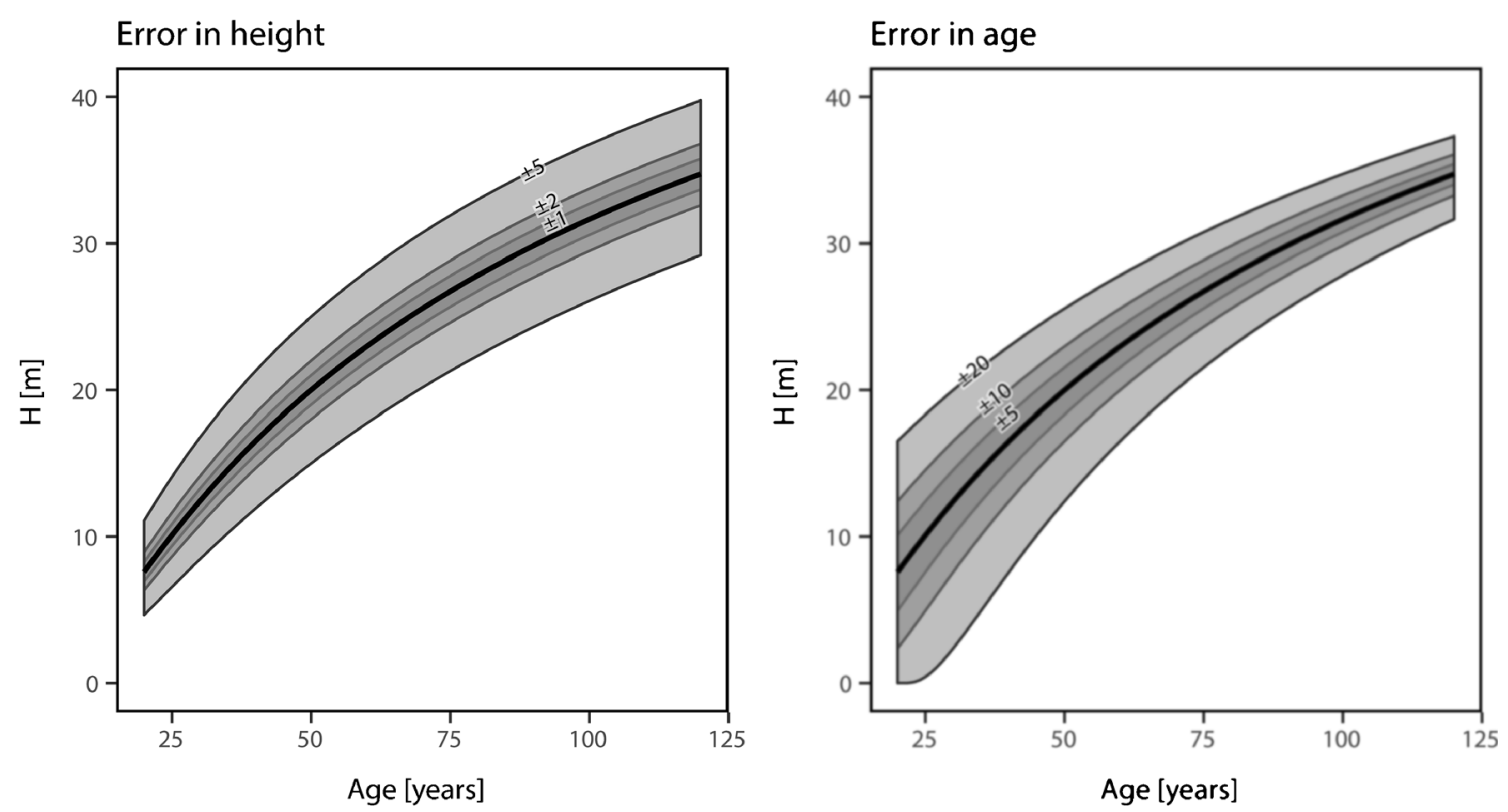

Fig. 5 Age-height curve and its variability resulting from errors in height (left panel) and age (right panel). Age-height curve was derived with site index model presented by [84], with a SI value of 20. We simulated the errors in height to be 1,2 , or $5 \mathrm{~m}$, and the errors in age to be 5 , 10 , or 20 years 